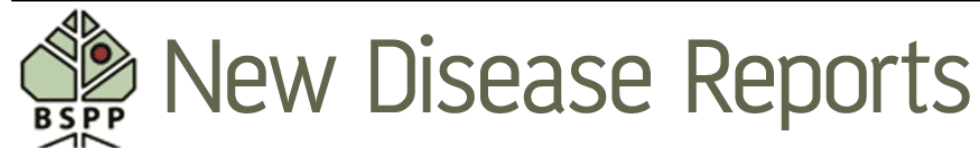

\title{
First report of Penicillium spp. and Pilidiella granati causing postharvest fruit rot of pomegranate in Spain
}

L. Palou*, A. Guardado and C. Montesinos-Herrero

Pathology Laboratory, Postharvest Technology Center, Valencian Institute for Agricultural Research (IVIA), Apartat Oficial, 46113 Montcada, Valencia, Spain

*E-mail:palou_llu@gva.es

Received: 24 Feb 2010. Published: 13 Oct 2010. Keywords: Punica granatum, blue mold

In a survey of pomegranate (Punica granatum) postharvest losses in commercial packinghouses in Spain, blue mould symptoms, or circular lesions of soft, brown tissues that expanded rapidly and were covered with globose yellowish pycnidia that turned to dark greenish-brown, were observed on up to $20 \%$ and $10 \%$ of pomegranates (cv. 'Mollar de Elche'), respectively. The potential causal agents were transferred to potato dextrose agar (PDA), purified and identified in the first case (blue mould) as Penicillium expansum Link, P. sclerotiorum J.F.H. Beyma, $P$. glabrum (Wehmer) Westling and P. minioluteum Diercks; and in the second case (pycnidia) as Pilidiella granati Saccardo. The identification was performed in the Spanish Type Culture Collection (CECT, UV, Valencia, Spain) by morphological observation of colonies growing on CYA (Czapek yeast extract agar), MEA (malt extract agar) and 25\% glycerol nitrate (G25N) agar(Pitt, 1979). Pilidiella granati produced cream-coloured colonies of velvety appearance and abundant dark brown to black spherical pycnidia (up to $130 \mu \mathrm{m}$ diameter). Hyphae were septate and conidia were hyaline, one-celled, ellipsoid to fusiform (average 11.4-17.5 x 4.4-3.3 $\mu \mathrm{m}$ ). The identification of all fungi was confirmed by the amplification and subsequent sequencing of the ribosomal DNA intragenic spacer regions ITS1 and ITS2 along with the 5.8S rRNA gene. Furthermore, the region D1/D2 in the 5' end of the 28S rDNA gene was also amplified and sequenced.

To fulfill Koch's postulates, 5-mm diameter mycelial plugs from seven-day-old colonies grown on PDA at $25^{\circ} \mathrm{C}$ (Figs. 1, 2) were aseptically transferred to skin wounds on superficially disinfected 'Mollar de Elche' pomegranates (one plug per fruit, 16 fruit per fungus). Wounded but not inoculated fruit were used as controls. While disease symptoms were observed after seven days incubation at $20^{\circ} \mathrm{C}$ on pomegranates inoculated with $P$. expansum, P. sclerotiorum, P. glabrum (Fig. 3) and Pilidiella granati (Fig. 4), no decay was observed on control fruit and fruit inoculated with $P$. minioluteum. The first four fungi were consistently reisolated from decayed fruit. Several Penicillium spp. and Coniella granati (Saccardo) (an obligate synonym of $P$. granati according to
MycoBank database) have been previously reported to cause postharvest pomegranate decay (Hebert \& Clayton, 1963; Labuda et al., 2004; Tziros \& Tzavella-Klonari, 2007; Bardas et al., 2009). However, to our knowledge, this is the first report of Penicillium expansum, $P$. sclerotiorum, P. glabrum and Pilidiella granati causing fruit rot in Spain.

\section{References}

Bardas GA, Tzelepis GD, Lotos L, Karaoglanidis GS, 2009. First report of Penicillium glabrum causing fruit rot of pomegranate (Punica granatum) in Greece. Plant Disease 93, 1347. [doi:10.1094/PDIS-93-12-1347A]

Hebert TT, Clayton CN, 1963. Pomegranate fruit rot caused by Coniella granati. Plant Disease Reporter 47, 222-3.

Labuda R, Hudec K, Piecková E, Mezey J, Bohovič R, Mátéová S, Lukác SS, 2004. Penicillium implicatum causes a destructive rot of pomegranate fruits. Mycopathologia 157, 217-23.

[doi:10.1023/B:MYCO.0000020599.95040.c6]

Pitt JI, 1979. The genus Penicillium and its teleomorphic states Eupenicillium and Talaromyces. London, UK: Academic Press. [doi:10.1002/jobm.19810210822]

Tziros GT, Tzavella-Klonari K, 2007. Pomegranate fruit rot caused by Coniella granati confirmed in Greece. Plant Pathology 57, 783. [doi:10.1111/j.1365-3059.2007.01798.x]

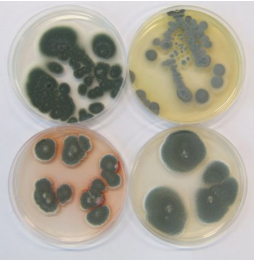

Figure 1

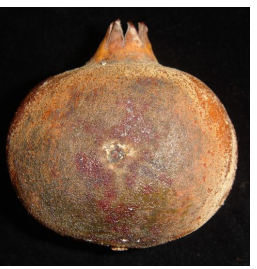

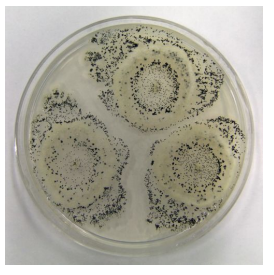

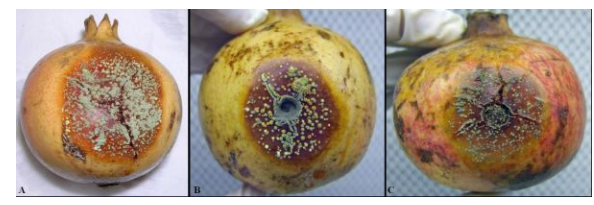

Figure 3

Figure 2

Figure 4

To cite this report: Palou L, Guardado A, Montesinos-Herrero C, 2010. First report of Penicillium spp. and Pilidiella granati causing postharvest fruit rot of pomegranate in Spain. New Disease Reports 22, 21. [doi:10.5197/j.2044-0588.2010.022.021]

(C) 2010 The Authors

This report was published on-line at www.ndrs.org.uk where high quality versions of the figures can be found. 